\title{
Universidade Acessível: com a Voz os Estudantes Surdos do Ensino MÉDIO $^{1}$ \\ ACCESSIBLE UNIVERSITY: THE DEAF STUDENTS OF SECONDARY EDUCATION HAVE THE FLOOR
}

\author{
Adelso Fidelis de MOURA ${ }^{2}$ \\ Lúcia Pereira LEITE 3 \\ Sandra Eli Sartoreto de Oliveira MARTINS ${ }^{4}$
}

\begin{abstract}
RESUMO: o sistema educacional tem dificultado o acesso à escola e/ou à classe bilíngue para os surdos, ofertando essencialmente o atendimento especializado no contraturno para alunos da Educaçáo Infantil e dos anos iniciais do Ensino Fundamental. Esse modo de organização do ensino, aliado à falta de reconhecimento dos estudantes surdos, enquanto grupo linguístico minoritário, colaboram para mantê-los afastados da universidade. O texto em questão retrata as expectativas de acesso ao Ensino Superior por estudantes surdos. Sete estudantes surdos, que utilizavam a Libras (Língua Brasileira de Sinais), participaram do estudo. Eles estavam matriculados no Ensino Médio em uma escola da rede pública estadual de ensino de um município do Oeste Paulista. Os dados foram coletados por meio de entrevistas individuais realizadas em Libras e filmadas para posterior transcrição para a Língua Portuguesa. A análise recaiu sobre o tema Expectativa de Acesso ao Ensino Superior. Os facilitadores e as barreiras reconhecidas por esses alunos para acessar o Ensino Superior foram identificadas. Grande parte dos alunos manifestou o desejo de ingressar na universidade e de continuar seus estudos. A falta de preparo e orientação da escola básica para garantir os conhecimentos científicos necessários a essa finalidade aliada à ausência do profissional tradutor/intérprete de Libras/Português no contexto universitário foram consideradas como os maiores obstáculos para o ingresso na universidade.
\end{abstract}

PALAVRAS-CHAVE: Educação Especial. Surdo. Língua Brasileira de Sinais. Ensino Superior. Ensino Médio.

\begin{abstract}
Education system has hindered the access to the school and/or bilingual class by deaf people, offering mainly specialized attendance for students of the Child Education and the earlier years of the Elementary School in the second shift. This way of organizing the education, added to the lack of recognizing of deaf students as a minority group collaborates to maintaining them away from the university. This text depicts the access expectations of deaf students to the Higher Education. Participants of this study are seven deaf students enrolled in the High School, at a state public school located on a town of the west of São Paulo State, who use the Brazilian Signal Language (Libras). Data were collected through individual interviews made in Libras, which were filmed for a further transcription into Portuguese language. Gathered material allowed to identify facilitators and obstacles recognized by those students to accessing the higher education. Most part of these students expressed their dream of entering in a university and continuing their studies. Lack of preparation and guidance of the basic school to ensure the need scientific knowledge to this finality, added to the absence of a Libras-Portuguese translator/interpreter in a university context, were considered by the interviewed deaf people as the main obstacles to admission to the university.
\end{abstract}

KEYWORDS: Special Education. Accessibility. Brazilian Signal Language. Deaf People. Higher Education. High School.

\section{INTRODUÇÃo}

Atualmente, a educaçáo de surdos na rede estadual de Sáo Paulo tem sido regida pelos princípios legais descritos na Política da Educação Especial na Perspectiva da Educação Inclusiva - PNEEPEI (BRASIL, 2008), que, dentre outros aspectos, preconizam sua escolariza-

\footnotetext{
${ }^{1}$ http://dx.doi.org/10.1590/S1413-65382317000400005

${ }^{2}$ Pós-Graduação em Psicologia - FC - UNESP/Bauru. moura.adelso@gmail.com

${ }^{3}$ Docente do Departamento de Psicologia e do Programa de Pós-Graduação em Psicologia do Desenvolvimento e da Aprendizagem, Unesp, Bauru, SP, Brasil. lucialeite@fc.unesp.br

${ }^{4}$ Docente do Departamento de Educação Especial e do Programa de Pós-graduação em Educação. Unesp, Marília, SP, Brasil. sandra.sartoreto@gmail.com
} 
ção em salas regulares, a partir da oferta de Apoio Pedagógico Especializado ( $\mathrm{APE}^{5}$ ), no turno inverso àquele em que estudam. A Educação Especial, sob essa prerrogativa, orienta o ensino de surdos na proposta pedagógica da escola. Os alunos surdos frequentam as salas comuns de ensino regular, com o acompanhamento de um intérprete de Libras/Língua Portuguesa, e recebem atendimento educacional especializado, em turmas de até cinco alunos, por profissionais com conhecimentos específicos em Libras, atendendo ao disposto na Resolução no 61 da Secretaria de Educação do Estado de São Paulo, de 11 de novembro de 2014 (SÃO PAULO, 2014).

Ainda no âmbito estadual, o apoio ao aluno surdo em sala de aula regular do Ensino Fundamental ou Médio conta com a presença de professor interlocutor ${ }^{6}$ da Libras/Língua Portuguesa. O termo interlocutor é usado na Resolução 38, de 16 de junho de 2009, e na Resolução 61, de 11 de novembro de 2014, para designar o tradutor/intérprete de Libras/ Língua Portuguesa, no estado de São Paulo. A primeira normativa que dispóe sobre a admissão de docentes com qualificação na Língua Brasileira de Sinais - Libras, nas escolas da rede estadual de ensino, traz à função os requisitos da formação e carga horária a ser cumprida na jornada de trabalho (SÃO PAULO, 2009).

Em termos nacionais, há outros regulamentos que orientam a atuação do intérprete de Libras, no ambiente escolar. O capítulo VII, da Lei 10.098/00, discorre sobre a acessibilidade à Língua de sinais, enquanto o inciso IV do artigo $8^{\circ}$ da Resolução no 2 , de 11 de setembro de 2001, institui Diretrizes Nacionais para a Educação Especial na Educação Básica. No entanto, é importante destacar que o Decreto no 5.626/05, o qual regulamenta a Lei no 10.436 , de 24 de abril de 2002, e dispóe sobre a Língua Brasileira de Sinais - Libras e a Lei no 10.098, de 19 de dezembro de 2000, em seu artigo 14, parágrafo $2^{\circ}$, ressalta que o intérprete não possui a mesma função do professor da sala regular. Sua função é de intermediar as relaçóes entre professor e aluno surdo, aluno surdo e aluno surdo, nos processos de ensino-aprendizagem (LACERDA, 2014).

A presença do intérprete de Libras na sala de aula objetiva possibilitar ao surdo receber informaçóes importantes que favoreçam seu desenvolvimento educacional. Porém, devem ser consideradas as diferenças no processo de inserção do intérprete, como, por exemplo, a idade do aluno surdo e o seu nível de ensino. Embora o decreto que regulamenta a educação de surdos, no Brasil, recomende o respeito às necessidades linguísticas dos alunos surdos, ainda há muito a ser feito para atendê-los de forma adequada, conforme relatado nos trabalhos de Lacerda e Bernardino (2014).

Sobre essa questão, é notório observar que a educação de surdos, no país, foi marcada por discursos e práticas de ensino reguladas por uma cultura que buscava a normatização e o controle de sua população (SKLIAR, 2013). As formas oficialmente reconhecidas de educação de surdos, somadas ao resultado ineficiente do nível de seu letramento, no Ensino Fundamental, constituem aspectos indispensáveis para problematizar os modos de organização, estrutura e funcionamento do ensino que orientam a escolarização dos surdos, na atualidade.

\footnotetext{
${ }^{5} \mathrm{O}$ Atendimento Pedagógico Especializado se diferencia do Atendimento Educacional Especializado, pela seleção dos alunos separados por tipo de deficiência. Professores especializados prestam atendimento e apoio aos alunos em salas de recursos específicas para cada área de deficiência (auditiva, visual, intelectual e física).

${ }^{6}$ Neste trabalho, usaremos o termo intérprete de Libras/Língua Portuguesa.
} 
Nesse contexto, ressalta-se a relevância de estudos que almejam investigar a percepção dos surdos sobre o ingresso no Ensino Superior. Conhecer as condiçóes que lhes são oferecidas pelas instituiçóes, para que possam concluir os estudos com êxito, se mostra pertinente pela dificuldade de sua promoção aos níveis mais elevados de ensino. Dessa forma, poderemos contribuir para desfazer estereótipos da sociedade em geral sobre a falta de capacidade desse grupo, no exercício de funçóes laborais mais complexas (PERLIN, 2013).

As estatísticas da Educação Superior no país, em 2013, referem que, dos 29.034 estudantes que declaram ter algum tipo de deficiência no ingresso à graduação, 1.448 se reconhecem como surdos e 7.037 com deficiência auditiva. $\mathrm{O}$ acesso dos surdos à universidade constitui uma prática incipiente, visto que, do total de alunos que se declaram com deficiência no Ensino Superior, estes correspondem a 5 \% segundo dados censitários do Instituto Nacional de Estudos e Pesquisas Educacionais Anísio Teixeira - INEP (BRASIL, 2014). Numa leitura mais detalhada dos que se identificaram surdos, muito destes, provavelmente, assim se designaram por serem usuários de uma língua diferente dos ouvintes - a Libras -, sendo o português denominado a segunda língua, reconhecida pela Lei 10.436 (BRASIL, 2002).

Esses dados problematizam o assunto pela percepção inexpressiva da presença do surdo, no meio universitário, se comparados à amostra total do público-alvo da Educação Especial, declarado pelo INEP (2014). Diante disso, este estudo tem como objetivo retratar as expectativas de estudantes surdos concluintes do Ensino Médio sobre as condiçóes de acesso à Universidade.

\section{A ESCOLARIZAÇÃo DE ESTUdANTES SURdOS FRENTE ÀS POLÍTICAS PÚBLICAS DE EDUCAÇÃO INCLUSIVA: EM FOCO O ENSINO MÉDIO NO BRASIL}

Atualmente, a sociedade de maneira geral tem valorizado discursos e açóes associados à inclusão social e educacional. Essa tendência pode ser o reflexo do crescimento da exclusão social presente na sociedade como um todo. No âmbito educacional, tem-se tentado reverter essa tendência, a partir de proposiçóes que procurem ofertar maiores oportunidades de formação acadêmica aos diferentes grupos sociais, incluindo aqui aqueles designados de pessoas com deficiência.

A inclusão escolar, apesar de ter sido citada na Constituição Federal de 1988, foi disseminada a partir da promulgação da Lei de Diretrizes e Bases da Educação Nacional (LDBEN 9.394/96), ganhando notoriedade no contexto educacional. Conforme os princípios constitucionais, a LDBEN, com base no artigo 58 (Capítulo V - Da Educação Especial), defende que o atendimento aos alunos com deficiência deverá acontecer preferencialmente em classes regulares, apoiados por serviços educacionais especializados, tais como: salas de recursos, itinerância e classes hospitalares. Assim como as Diretrizes Nacionais para a Educação Especial na Educação Básica (BRASIL, 2001), a LDBEN também concebe a Educação Especial como modalidade de ensino.

Carvalho (2013), em sua análise sobre a educação inclusiva, nos chama a atenção para o reducionismo da definição dessa expressão, uma vez que está associada imediatamente ao aluno com deficiência. Contudo, ela não foi idealizada para um grupo exclusivo, mas com o propósito de garantir a oportunidade de escolarização para todos, consistindo em um processo

${ }^{7}$ A Lei de Diretrizes e Bases da Educação Nacional (LDBEN) foi atualizada pela Lei no 12.796, de abril de 2013. 
interminável, o qual não pode ser guiado por decretos e modismos. Dessa forma, a proposta da educação inclusiva supera a promoção do ensino em espaço comum, pois exige transformação substancial, desde a formação do professor até a sensibilização sobre as diferenças entre todos os alunos que frequentam a escola (LEITE; MARTINS, 2012).

Embora muitos passem a afirmar que a educaçáo inclusiva decorra do movimento de integração de alunos com deficiência no ensino regular, uma não pode ser tomada como a evolução da outra, conforme esclarece Rodrigues (2006). Para subsidiar essa afirmação, é preciso considerar que a integração não alterou os valores não inclusivos da escola, pois criou espaços paralelos; sua visão de diferença está associada à deficiência; além da proposta de condicionamento do aluno com deficiência, ou seja, ele pode estar no espaço escolar comum, desde que mantenha um comportamento desejável.

Os Parâmetros Curriculares Nacionais da Educação Especial, ao defenderem a educação inclusiva, apontam para a necessidade de investimentos na formação do professor, o reconhecimento da igualdade de direitos e de oportunidades educacionais de todos os alunos e a construção de um ambiente educativo favorável para a superação dos obstáculos, o qual assuma a diversidade do seu alunado presente no espaço escolar (BRASIL, 1999b).

As diferenças entre as pessoas estão associadas muitas vezes a fatores genéticos, sociais, cronológicos, de gênero, psicossociais, socioeconômicos, culturais e étnicos. Com respeito às pessoas com deficiência, as diferenças podem ocorrer por patologias congênitas ou adquiridas, assumindo caráter vantajoso ou desvantajoso, de acordo com a relação que elas estabelecem com o meio físico ou cultural. A compreensão da deficiência depende da forma como ela é interpretada e abordada, dentro de um contexto social. Tal compreensão pode estar centrada tanto na deficiência como no meio. O discurso da inclusáo busca redirecionar esse foco para o meio, o qual deve ser o ponto das mediaçôes, correspondendo às necessidades de cada aluno (OMOTE, 2008).

A título de conceituação, a Lei Brasileira de Inclusão (BRASIL, 2015) define pessoa com deficiência, no seu art. 2, como aquela "[...] que tem impedimento de longo prazo de natureza física, mental, intelectual ou sensorial, o qual, em interação com uma ou mais barreiras, pode obstruir sua participação plena e efetiva na sociedade em igualdade de condiçóes com as demais pessoas." (BRASIL, 2015).

O mesmo documento reafirma o direito de escolarização das pessoas com deficiência preferencialmente na rede regular de ensino, sendo a escola responsável pelo atendimento às demandas educacionais. Atribui-se a ela, por conseguinte, a necessidade de se reconfigurar, a fim de vencer os desafios de tornar-se um espaço comum a todos os alunos, rumo à consolidação de uma sociedade mais inclusiva.

Balizado pela Política Nacional de Educação Inclusiva - PNEEPEI (BRASIL, 2008) -, tem-se o conhecimento de que a Educação Especial passa a compor a proposta pedagógica da escola, complementando ou suplementando as práticas e os conteúdos desenvolvidos no ensino regular, distanciando-se de uma ação paralela, sendo configurada como modalidade que perpassa todos os níveis de ensino, portanto, desde a educação infantil até o nível superior. Assim, o aluno da Educação Especial conta com o apoio do atendimento educacional especializado, no turno inverso àquele em que ele estuda, na classe comum, oferecido na própria escola ou em 
centros especializados. No Ensino Superior, tal propositiva não é diferente: a permanência e a participação do seu alunado devem estar garantidas na oferta de recursos e de açóes que possibilitem acessibilidade arquitetônica, de comunicação, informaçóes e dos materiais didáticos e pedagógicos, desde o processo seletivo ao desenvolvimento das atividades do ensino, à pesquisa e à extensão desenvolvidas no contexto universitário.

Aliadas a essas ponderaçóes, acrescentam-se as mudanças ocorridas na forma de conceber a educação para os surdos, no Brasil, a partir dos estudos realizados por Lodi (2013), em decorrência da promulgação da PNEEPEI. A autora destaca que as formas de organização escolar para os surdos, contempladas por essa política, atribuem ao intérprete a responsabilidade de garantir a comunicação em Libras em sala de aula, no entanto, a sua função e formação profissional ficam indefinidas na educação do surdo. Além dessa questão, critica o fato de que o ensino da Libras ocorra no contraturno, ou seja, no atendimento educacional especializado (AEE), para a Educação Infantil e séries iniciais de escolarização aos surdos. Nas palavras da autora (2013), medidas como esta colaboram para manutenção de um currículo monolíngue, no qual a Libras tem sido tratada como recurso assessório e/ou instrumental à formação acadêmica dos estudantes surdos.

Contrária à política, Lodi (2013) aponta para a necessidade de que a educação bilíngue aconteça por meio da oferta de classes de instrução em Libras - com aulas ministradas por professores bilíngues, em ambientes regulares de ensino e/ou em escolas para surdos, nas quais o português escrito seja ensinado como segunda língua, fatos não contemplados na PNEEPEI. Tal perspectiva prioriza que a criança surda vivencie situaçóes de aprendizagem da segunda língua, a partir da compreensão e significação na sua primeira língua, tendo em vista sua constituição balizada pelos processos históricos, socioculturais e ideológicos (BAKHTIN; VOLOCHINOV, 1999), na formação da consciência individual dos que a utilizam. Nesse sentido, entende-se que o desenvolvimento de linguagem/apropriação da Libras pelos alunos surdos incidirá nos primeiros anos escolares, sendo este assegurado e, por conseguinte, capaz de garantir "[...] uma sólida base educacional”, desenvolvida “[...] em uma língua acessível aos alunos”, possibilitando propor novos modos de organização escolar para os anos finais do Ensino Fundamental, o Ensino Médio e a educação profissional (LODI, 2013, p. 54).

No cenário atual, apesar de a PNEEPEI ser amplamente disseminada como um avanço na história da educação para o alunado da educação especial, o Decreto 5.626/05 tem sido considerado como mais adequado para orientar os anseios das comunidades surdas matriculadas no Ensino Médio, no Brasil. De acordo com Sá (2010), a oferta da educação básica ao deficiente, definida pela PNEEPEI, coopera para agravar o desrespeito às condiçóes linguísticas especiais desse grupo, preso ao analfabetismo funcional. Dito de outro modo, não basta reconhecer o direito de esse grupo ingressar na universidade: há que se oferecer as condiçóes para nela permanecer e concluir com êxito os estudos acadêmicos (VALENTINI; BISOL, 2012).

As consideraçóes anteriores demonstram os problemas de escolarização dos surdos, nas etapas que antecedem a educação superior, e convocam os profissionais a perceberem o abismo entre as políticas vigentes e os desafios sociais, linguísticos e pedagógicos que impóem pensar a surdez e a educação dos surdos, buscando legitimar as reivindicações das comunidades surdas enquanto não ouvintes. 


\section{Procedimentos para a ReAlizaçáo da PESQUisa}

Constituiu a amostra desta investigação um grupo de sete estudantes com diagnóstico de surdez, matriculados no Ensino Médio, que frequentavam a sala de recursos de uma escola estadual de um município do Oeste Paulista. Todos são do sexo masculino, com idade entre 15 e 25 anos, e se comunicam por meio da Libras. Os nomes dos participantes referenciados ao longo do texto são fictícios, em atendimento à garantia de anonimato prevista na normativa da Comissão Nacional de Ética em Pesquisa (CONEP). É oportuno informar que este estudo foi submetido à análise do Comitê de Ética em Seres Humanos, tendo sido aprovado pelo parecer $n^{\circ}$ 956.518. A coleta de dados foi consentida mediante a assinatura do Termo de Consentimento Livre e Esclarecido. Para os participantes menores de 18 anos, o termo de anuência autorizando a participação na pesquisa foi assinado pelos pais ou responsáveis. Informamos ainda que a unidade escolar, na qual ocorreu o desenvolvimento do estudo, manifestou-se favoravelmente à sua realização.

O quadro, a seguir, mostra o perfil dos alunos participantes e informações obtidas por meio de autodeclaração:

\begin{tabular}{|c|c|c|c|c|}
\hline Participante & Idade & Escolaridade & $\begin{array}{c}\text { Perfil de } \\
\text { comunicaçáo }\end{array}$ & Contexto escolar \\
\hline Samuel & 25 & $\begin{array}{l}2^{\circ} \text { ano do Ensino } \\
\text { Médio }\end{array}$ & Libras & $\begin{array}{l}\text { Acompanhamento do intérprete, desde o início } \\
\text { de sua escolarizaçáo. Estudou até o } 6^{\circ} \text { ano do } \\
\text { E.F. e retornou, quando constatou que havia } \\
\text { intérprete na EJA. }\end{array}$ \\
\hline Sandro & 25 & $\begin{array}{l}3^{\circ} \text { ano do Ensino } \\
\text { Médio }\end{array}$ & Libras & $\begin{array}{l}\text { Acompanhamento do intérprete, desde o início } \\
\text { de sua escolarizaçấo. }\end{array}$ \\
\hline Sérgio & 20 & $\begin{array}{l}3^{\circ} \text { ano do Ensino } \\
\text { Médio }\end{array}$ & Libras & $\begin{array}{l}\text { Acompanhamento do intérprete, a partir do } 6^{\circ} \\
\text { ano do Ensino Fundamental. }\end{array}$ \\
\hline Saulo & 19 & $\begin{array}{l}3^{\circ} \text { ano do Ensino } \\
\text { Médio }\end{array}$ & Libras & $\begin{array}{l}\text { Acompanhamento do intérprete, a partir do } 6^{\circ} \\
\text { ano do Ensino Fundamental. }\end{array}$ \\
\hline Santos & 15 & $\begin{array}{l}1^{\circ} \text { ano do Ensino } \\
\text { Médio }\end{array}$ & Libras & $\begin{array}{l}\text { Acompanhamento do intérprete, desde o início } \\
\text { de sua escolarizaçáo. }\end{array}$ \\
\hline Sílvio & 20 & $\begin{array}{l}3^{\circ} \text { ano do Ensino } \\
\text { Médio }\end{array}$ & Libras & $\begin{array}{l}\text { Acompanhamento do intérprete, a partir do } 7^{\circ} \\
\text { ano do Ensino Fundamental. }\end{array}$ \\
\hline Sidney & 20 & $\begin{array}{l}2^{\circ} \text { ano do Ensino } \\
\text { Médio }\end{array}$ & Libras & $\begin{array}{l}\text { Escolarização até o } 6^{\circ} \text { ano do Ensino Funda- } \\
\text { mental, exclusivamente com surdos em escola } \\
\text { bilíngue. Não se adaptou à escola inclusiva, } \\
\text { interrompendo seus estudos e retornando à EJA, } \\
\text { no E. M. }\end{array}$ \\
\hline
\end{tabular}

Quadro 1 - Caracterização dos participantes

Legenda: E.F. - Ensino Fundamental; EJA - Educação de Jovens e Adultos; E.M. - Ensino Médio.

Fonte: elaboração própria.

A pesquisa foi feita em uma escola pública estadual de um município do Oeste Paulista, onde os alunos recebem apoio escolar em sala de recursos. Essa escola atendia a alunos do Ensino Fundamental ciclo II e Ensino Médio, nos períodos da manhã, tarde e noite. 
Os alunos eram atendidos em sala de recursos para oferta do atendimento educacional especializado no contraturno do qual eles estudavam. Esse atendimento ocorria duas vezes por semana para cada aluno, por até duas horas-aula. No turno regular de ensino em sala de aula comum, os participantes eram acompanhados por um profissional intérprete de Libras ${ }^{8}$, incumbido de possibilitar a comunicação em sala de aula, favorecendo a interação entre surdos e ouvintes.

A coleta dos dados foi feita por intermédio de entrevista semiestruturada com os participantes da pesquisa, subsidiada por um roteiro norteador de perguntas sobre o tema da investigação. A entrevista foi aplicada primeiramente em situação-piloto, com participante com perfil semelhante, para que fossem feitos os ajustes e aperfeiçoamentos necessários para a coleta definitiva de dados.

As entrevistas, que tiveram duração mínima de 30 minutos, foram filmadas e efetuadas pelo pesquisador em Língua Brasileira de Sinais, que atuava como professor da sala de recursos no local de realização da pesquisa, em dia e horário previamente combinados.

\subsection{Procedimento de tratamento dos dados}

Das respostas dadas às questôes mencionadas no roteiro de entrevistas, foram levantados os quatro eixos de análise: Apropriação do desenvolvimento linguístico; Descrição do percurso educacional; Implicaçôes na relação entre surdos e com ouvintes; Expectativas de acesso ao Ensino Superior. Neste texto, serão abordadas as referentes ao tema Expectativa de acesso ao Ensino Superior. O tema em questão procurou agrupar os relatos dos participantes sobre o conhecimento e a percepção que o participante mencionava, diante da possibilidade de frequentar o Ensino Superior, em resposta às questóes: $\mathrm{O}$ que representa o Ensino Superior? Como deveria ser uma faculdade que atenda às necessidades do surdo? Quais as possibilidades que o nível superior de ensino pode trazer para sua vida?

Após a transcrição em Libras e em Língua Portuguesa de todas as entrevistas, foram criados tópicos temáticos, com base na classificação dos elementos encontrados nas respostas dos participantes, durante a entrevista.

Com os dados em mãos, o pesquisador pôde sugerir inferências e adiantar interpretaçóes, de acordo com os objetivos propostos. O conjunto de informaçóes recolhidas foi organizado em três tópicos temáticos formulados no momento da análise dos dados, a partir da identificação dos conteúdos recorrentes e procurando atribuir sentido às respostas dos participantes: a) Expectativa de frequentar o Ensino Superior; b) Condiçóes de acesso e/ou permanência no Ensino Superior; c) Das instituições e relevância do Ensino Superior.

\section{Resultados E discussāo}

Os resultados se referem à análise das sete entrevistas com alunos surdos do Ensino Médio, identificando e descrevendo os facilitadores e as barreiras reconhecidas por eles, para o seu acesso ao Ensino Superior, nos três tópicos temáticos explicitados na sequência.

\footnotetext{
${ }^{8}$ Resolução $n^{o} 38$, de 19 de junho de 2009. Dispóe sobre a admissão de docentes com qualificação na Língua Brasileira de sinais Libras, nas escolas da rede estadual de ensino. Lei no 12.319 , de $1^{\circ}$ de setembro de 2010. Regulamenta a profissão de Tradutor e Intérprete da Língua Brasileira de Sinais - LIBRAS.
} 


\subsection{EXPeCtaTiva De FReQuentar o Ensino Superior}

Lembramos que os fragmentos das respostas dos sujeitos entrevistados foram traduzidos da língua de sinais para a Língua Portuguesa e se apresentam aqui em itálico.

Dos sete participantes, quatro declararam intenção em entrar na faculdade para cursar o Ensino Superior. Três não demonstraram interesse, por motivos diferentes, como observado. Samuel relata que quer muito ir para a faculdade: "Eu tenho vontade, sonho; tenho muita vontade de ir para faculdade. "Sandro quer fazer um curso de informática, antes da faculdade: "No SENAI, tem mecânica; eu quero ir e depois informática na faculdade." Saulo pretende entrar na faculdade, após concluir o curso de mecânica que está fazendo no SENAI. "Acabando o $3^{\circ}$ colegial, vou para a faculdade. Eu posso aprender mecânica na faculdade... No futuro." Já Sidney pretende fazer faculdade de Educação Física em São Paulo.

Dos que não têm interesse, Sérgio não quer ir para a faculdade porque acredita não ter condiçóes de passar no vestibular: "Eu acho que eu não passo na faculdade. Eu acho que eu não consigo. É difícil. É fácil pra você. A dificuldade maior na faculdade é ter que anotar tudo. "Sílvio não vai, porque recebe uma aposentadoria: "Não... Eu sou aposentado. "Santos prefere trabalhar, antes de ir para a faculdade; dessa forma, não a tem como prioridade: "Vou trabalhar, descansar e depois fazer a faculdade."

Conforme os dados do INEP, discutidos por Martins, Leite e Lacerda (2015), apesar do aumento de matrículas de pessoas com deficiência no Ensino Superior, sobretudo após a criação do Programa Incluir/MEC, ainda existe uma inexpressividade de estudantes surdos nesse nível de ensino. Tais dados sustentam os achados deste estudo, os quais indicam que a maioria dos participantes não conhece surdos que estudem ou tenham estudado no Ensino Superior. Samuel conhece um surdo que começou a faculdade, mas abandonou após um ano de curso: "Conheço um que me falou que, com o passar do tempo, desanimou. Depois de mais ou menos dois anos, desanimou. "Sandro conhece dois que estudam em faculdade em uma cidade próxima: "Tem dois surdos em Agudos que estão na faculdade. "Sidney só viu surdos universitários em São Paulo: "Surdo na faculdade aqui não tem... Em São Paulo sim, sempre tem. Têm muitos surdos. $O$ grupo que eu estudava antes cresceu, se formou no $3^{\circ}$ colegial e foram para a faculdade. "Para Saulo, não há surdos na faculdade; a universidade é para os ouvintes: "Surdo nunca entra, não tem. São todos ouvintes."Tal posicionamento é compartilhado por Sérgio: "Não. Não tem surdo, eu nunca $v i$. "Santos justifica a ausência do surdo no Ensino Superior, pelo fato de não haver intérpretes nas faculdades: "Na faculdade não tem intérprete. Não tem surdo." Bisol, Valentini, Simioni e Zanchin (2010) relatam, em sua pesquisa sobre a inclusão de surdos no Ensino Superior, que, mesmo com o acompanhamento do intérprete de Libras, o ambiente universitário é regido por normas do mundo ouvinte e, por isso, exige grande esforço de adaptação para o surdo, uma vez que as diferenças linguísticas e sensoriais configuram-se muitas vezes em elemento dificultador no estabelecimento das relaçóes sociais.

Silva e Martins (2016) apontam que, com o passar dos anos, as políticas de inclusão favoreceram a abertura de vagas no Ensino Superior, porém, ainda há um longo caminho a percorrer para abrigar a todos os que desejam cursá-lo. A despeito dos esforços em favor da democratização do ensino, inúmeros são os obstáculos que marcam a exclusão das pessoas com deficiência das oportunidades de usufruir de níveis mais elevados de formação. Todavia, não 
se pode ignorar que o acesso à universidade implicará, para esse grupo, sobrepujar os modos de organização do vestibular ou Exame Nacional do Ensino Médio (ENEM), que, em geral, desatendem às normativas de acessibilidade para essa etapa de educação em conformidade, por exemplo, com o Decreto no 3.298 (BRASIL, 1999a), a Portaria no 3.284 (BRASIL, 2003) e a Circular no 277 (BRASIL, 1996a).

\subsection{Condiçóes De aCesso E/OU PERMANÊNCIA No Ensino SuPERIOR}

Para a totalidade dos participantes, a condição de acesso e de permanência do surdo no Ensino Superior se torna difícil, diante da ausência de intérprete de Libras, considerando o nível de compreensão e o domínio da Língua Portuguesa que apresentam.

Sérgio destaca a importância de se atender às necessidades do surdo, desde os processos seletivos para ingresso no Ensino Superior: "O surdo precisa muito entrar. O surdo quer prova do ENEM gratuita em Libras. "Santos ainda diz ter capacidade de aprender, se houver intérprete na faculdade: "Eu posso estudar em Libras. O intérprete me mostra o que o meu professor me ensina; eu tenho vontade de estudar. "Como em todo sistema escolar, para os participantes, os surdos necessitam de intérprete de Libras na faculdade, contudo, não conhecem os procedimentos para que seja possível a presença desse profissional. Os relatos tendem a simplificar esse processo, como a opiniāo de Santos: Eu chamo o (sinal do intérprete) pra ficar junto comigo. Ele senta do meu lado e pronto, tá resolvido!", ou assumir a responsabilidade, como é o caso de Sidney:

Ou eu ou a faculdade paga. Eu ou ela. A própria pessoa chama, a faculdade não se manifesta, não fala nada. Eu penso sozinho, faltam intérpretes. Eu não entendo a fala. Falta comunicação, eu não entendo. Aproveito e chamo e pago. A faculdade não fala em intérprete. Então, eu procuro, entrego o contato, eles se falam por telefone, aí eles pagam e trocamos.

Assinala Samuel: "O difícil é ler, porque eu sei pouco. Lá no vestibular, não tem intérprete, e isso é difícil porque ninguém passa”. Há também a falta de conhecimento sobre como acessar a universidade. Saulo desconhece as condições de acesso: "Não sei como entrar. Conheço intérpretes que vão pra faculdade, mas, como entrar, eu não sei."

Sobre a presença do intérprete de Libras, todos os participantes afirmam desconhecer a existência desse profissional, na faculdade, e não têm a expectativa de alteração desse quadro nos próximos anos. Porém, Sandro explicita o processo que entende como viável para a contratação do intérprete pela faculdade:

Eu preciso pedir. Precisa porque é importante a ajuda do intérprete na faculdade para trocar informaçôes, aprender a escrever. Como o professor vai ensinar o surdo? Faltam intérpretes para aprender e fala pra ela e ela fala pra mim, eu entendo e amplio meus conhecimentos. O professor precisa falar para o intérprete, e ele explica o que aprendeu, e amplio meus conhecimentos; isso é preciso [...] Primeiro pede para o diretor deixar, procurar o decreto de lei para o diretor entender que o surdo precisa da ajuda do intérprete, e ele deixa.

Samuel reconhece a necessidade do intérprete de Libras na faculdade: "Mas precisamos do intérprete. Precisa de um intérprete. Precisa falar para as pessoas da faculdade que precisamos 
do intérprete... As palavras são difíceis. Com intérprete, aprendo e passo. "Para Saulo, o intérprete ajuda a entender as palavras difíceis e explicar o que ele tiver dificuldade para compreender, no entanto, declara a necessidade de independência do surdo, na leitura: "O surdo precisa responder, ler sozinho e também ter a explicação do intérprete."

O intérprete é fundamental para os participantes, de modo que Sidney aventa a possibilidade de remunerar o intérprete com recursos próprios, se a faculdade se recusar a fazê-lo, para poder ingressar no Ensino Superior:

[...] Ou eu ou a faculdade paga. Eu ou ela. A própria pessoa chama, a faculdade não se manifesta, não fala nada. Eu penso sozinho, faltam intérpretes. Eu não entendo a fala. Falta comunicação, eu não entendo. Aproveito e chamo e pago. A faculdade não fala em intérprete. Então eu procuro, entrego o contato, eles se falam por telefone, aí eles pagam e trocamos.

Observamos que Samuel não possui conhecimento de nenhuma instituição de Ensino Superior que tenha a possibilidade de solicitar um intérprete para acompanhá-lo, sendo esse o motivo pelo qual o surdo não presta o vestibular. Notamos que a presença do intérprete é colocada como fundamental para o surdo acessar e permanecer em todos os níveis de ensino.

Nos relatos, evidencia-se que, para os surdos, sem o intérprete é impossível estudar em uma faculdade. A despeito do Decreto 5.626 (BRASIL, 2005), a presença desse profissional na universidade não é a realidade em todas as instituições de nível superior. Tal situação é confirmada por um estudo de Cruz (2007), a propósito de pesquisa efetuada com surdos universitários na região norte do Estado de São Paulo, a qual demonstrou que eles não têm o acompanhamento de um intérprete de Libras, sendo responsabilizados por sua própria aprendizagem.

\subsection{Das INSTITUIÇÓES E RELEVÂNCIA do EnSINo SUPERIOR}

As instituições de ensino superior (IES) têm proliferado, no país, nos últimos anos. Em termos amostrais, em 2015, segundos dados do Censo do Ensino Superior (BRASIL, 2016), o Brasil conta com 2.364 instituiçôes que oferecem mais de 33 mil cursos de graduação. Entretanto, os participantes desta pesquisa demonstram ter pouco contato com esse contexto. Dos sete participantes, um declara não conhecer nenhuma faculdade; outro conhece apenas escolas técnicas de cursos profissionalizantes; três deles confundem nomes de faculdades com os de escolas técnicas, enquanto somente dois declaram conhecer presencialmente algumas IES. Isso revela o distanciamento da possibilidade de estudantes surdos ingressarem no Ensino Superior. De acordo com Skliar (2013), a mínima proporção de alunos surdos, nesse nível de ensino, pode ser tomada como um retrato do fracasso sistema escolar oferecido a eles, uma vez que este é apoiado na língua oral, de sorte que sua ausência acaba por produzir sujeitos analfabetos, sem condiçôes de competir em postos mais elevados no mercado de trabalho.

Mesmo não sabendo informar claramente sobre as IES, ou pouco as conhecendo fisicamente, todos os entrevistados valoram positivamente o ingresso no Ensino Superior, pois, para eles, isso é muito importante, por possibilitar o desenvolvimento pessoal, ascensão profissional e financeira. O relato de Saulo é uma amostra disso: "O surdo precisa ir pra faculdade. É bom aprender para se desenvolver, é importante. Por exemplo, no trabalho consegue um bom 
salário." Sidney faz comentário semelhante: “[...] porque, com a faculdade, o dinheiro é bom no futuro; pode ter uma casa grande, viajar, conhecer cidades, ir para a chácara, entendeu?"

Nas falas dos participantes, fica evidente que as perspectivas futuras de crescimento profissional estão fortemente atreladas à possiblidade de conclusão do Ensino Superior. Para eles, depois do término da faculdade, há chance de um bom salário, de promoção funcional, de poder juntar dinheiro e escolher um bom emprego. Santos define seu pensamento desta forma: "Quando se tem a faculdade, ganha dinheiro mais rápido, e dá pra comprar carro, casa, estudar[...] Estudar muito. Chega no final do ano e conseguir guardar dinheiro com tranquilidade. Se tiver vontade de viajar de avião, consegue. "É relevante enfatizar que os valores não sáo acadêmicos. A relevância é retratada como possibilidade de acesso aos bens materiais e a interesses que decorrem do poder aquisitivo.

Sidney faz uma distinção entre os que fazem faculdade e os que não fazem, ressaltando ainda a visibilidade positiva disso: "Por exemplo, eu mostro que já fiz a faculdade. Ele se admira! [...] Pra quem estuda o $3^{\circ}$ colegial, o salário é pouco; quem estuda na faculdade, o salário é bem maior."

Sobre o trabalho dos surdos, Santos comenta que o "[...] surdo vai trabalhar onde tem vagas de emprego por um salário baixo. O surdo vai trabalhar porque não quer ir pra faculdade", reconhecendo que ter um curso superior pode trazer melhores salários, quando comparado a quem não quer fazer uma faculdade.

Sá (2010) enfatiza que a educação oralista tradicional oferecida aos surdos foi insuficiente para que conseguissem alcançar o Ensino Superior. Por demonstrarem um domínio insuficiente do português escrito e um baixo grau de letramento, nessa língua, receberam uma educação meramente profissional, a fim de que pudessem acessar o mercado de trabalho. Apesar de os dados de matrícula do INEP (BRASIL, 2014) revelarem haver a presença de estudantes surdos matriculados em cursos universitários, acredita-se que o aumento dessa demanda se relaciona à formulação e aplicação das Políticas Afirmativas, as quais apoiam a eliminação de barreiras de acesso daqueles que estiveram, por longas décadas, afastados dessa etapa de educação. Aliada a esse contexto, no caso dos estudantes surdos, a oferta de vagas em cursos de Letras-Libras e Pedagogia bilíngue, ${ }^{9}$ no Brasil, parece alargar as possibilidades da busca pela sonhada formação universitária.

Na mesma direção e, ainda, expressa em termos legislativos, a participação das pessoas com deficiência no Ensino Superior, embora em menor número, tem conquistado os bancos das Instituições de Ensino Superior, no âmbito público e privado (BRASIL, 2014). Como exemplo de açóes nessa perspectiva, destaca-se a Lei $13.409 / 2016,{ }^{10}$ a qual foi aprovada

\footnotetext{
${ }^{9}$ A Universidade Federal de Santa Catarina (UFSC/SC) foi a pioneira na oferta e disseminaçấo de propostas de formação de professores para o ensino Libras, nas séries finais do Ensino Fundamental, em Letras-Libras, enquanto o Instituto de Educação de Surdos (INES/RJ) destaca-se pela promoção de cursos de formação de professores para atuar nas séries iniciais, por meio da oferta da Pedagogia Bilíngue.

${ }^{10}$ Essa lei, a qual altera a Lei No 12.711/2012, reza, em seu em Art. 10: "As instituiçōes federais de educação superior vinculadas ao Ministério da Educação reservarão, em cada concurso seletivo para ingresso nos cursos de graduaçấo, por curso e turno, no mínimo 50\% (cinquenta por cento) de suas vagas para estudantes que tenham cursado integralmente o ensino médio em escolas públicas. Estas serão preenchidas por autodeclarados pretos, pardos e indígenas nos termos da legislaçáo", sendo acrescida, mais recentemente, essa condição às pessoas com deficiência. Para obter mais informaçôes, consultar: http://www.planalto.gov.br/ccivil_03/_ato2015-2018/2016/Lei/L13409.htm. Acesso em: 20/03/2017
} 
recentemente, sobre a reserva de vagas para pessoas com deficiência nos cursos técnicos de nível médio e superior das instituições federais de ensino.

Entre os três participantes que não demonstraram a intenção de ingressar em uma faculdade, após a conclusão do Ensino Médio, Sérgio pretende fazer informática: "No curso, tem intérprete de Libras; no curso do SENAC tem. Ele escreve na lousa, eu olho e digito no computador só. Aprendo lá com Libras. "Santos quer fazer um curso técnico de mecânica no SENAI e Sílvio planeja "[...] passear, namorar e ir na academia".

Embora reconheçam a importância e a possibilidade de um futuro melhor, os participantes acabam por pensar em caminhos alternativos, considerando-os mais fáceis e acessíveis para o surdo, como a participação em cursos técnicos profissionalizantes. Quatro dos sete participantes acreditam que o surdo, mesmo com suas limitaçóes, tem condiçóes necessárias para a continuidade dos estudos, em nível superior, mas precisa que sua forma de comunicação seja levada em conta e garantida. Isso requer, tanto das escolas de Ensino Médio como das instituiçóes de ensino universitário, açóes que tornem possível a presença do surdo, de forma efetiva e significativa.

Galvadão (2017), ao se referir ao caso de uma estudante surda matriculada em um curso universitário, alerta para importância de ações institucionais que garantam a contratação de profissionais qualificados para mediar a comunicação com os surdos, em sala de aula, com destaque para a presença do TILSP (Tradutor Intérprete de Língua Brasileira de Sinais/Língua portuguesa). Nesse contexto, caberá a esse profissional participar do processo de preparação de aulas com os professores, acessar o conteúdo previamente para a leitura, compreensão e reflexão sobre a melhor maneira de transmitir os significados e conceitos ao surdo, além do diálogo constante com os docentes, sobre o desempenho acadêmico dos surdos, num trabalho de parceria. A precarização da oferta desse serviço pode dificultar e/ou atrasar que estudantes surdos avancem academicamente e concluam com êxito a sua graduação.

\section{CONSIDERAÇÓES}

$\mathrm{Na}$ trajetória escolar dos surdos, percebemos que, ao concluírem o Ensino Médio, muitos se dirigem exclusivamente ao mercado de trabalho, distanciando-se do Ensino Superior. Tal constatação nos incitou à realização deste estudo. Na verdade, trabalhos ligados ao tema (QUADROS, 1997; QUADROS; KARNOPP, 2004; GOES, 2012; SKLIAR, 2013; LACERDA; BERNARDINO, 2014) confirmaram o insucesso da educação oferecida para os surdos, no Brasil. Skliar (2013) salienta que a escola é organizada pelos e para os ouvintes e pela representação que se tem do sujeito surdo, desconsiderando a sua língua e cultura, resultando na baixa proporção de surdos no Ensino Superior.

Com relação ao objeto de investigação do estudo aqui retratado, a saber, Expectativas de acesso ao Ensino Superior, embora as condiçóes de acesso ainda lhes sejam difíceis, a pesquisa mostrou que os alunos surdos que estão no Ensino Médio têm o desejo de ingressar na Universidade e de continuar seus estudos. Entretanto, falta preparo e orientação da escola básica em formá-los, para que possam se apropriar de conhecimentos necessários a fim de ingressarem no Ensino Superior. 
Em uma recente investigação efetuada por Martins e Lacerda (2015) sobre o Exame Nacional do Ensino Médio (ENEM) e o acesso de estudantes surdos ao Ensino Superior brasileiro, foi constatado que a média dos estudantes surdos, nesse exame, é de 360,82 pontos, não alcançando a média esperada de 500 pontos para aprovação. Esse resultado reitera o posicionamento anterior, indicando que a educação ofertada para os surdos ainda está aquém da qualidade esperada, deixando de oferecer condiçôes de ensino que os alavanquem a níveis mais elevados de aprendizagem. Traçar a projeção da educação de surdos no Ensino Superior, no país, é tarefa complicada, pois é necessário compreender que as políticas vigentes não contemplam, de fato, as necessidades educacionais desses sujeitos em níveis anteriores, uma vez que o sucesso acadêmico do surdo decorre de um processo formativo capaz de promover o desenvolvimento da sua língua e valorizar sua cultura, de modo a lutar contra essa uniformização de modelo que limita e oprime o ensino.

$\mathrm{Na}$ análise dos relatos do conjunto dos participantes, foi possível observar que a possibilidade de cursar a universidade está relacionada à visibilidade positiva de uma carreira profissional com melhores condiçóes de trabalho, salários mais elevados e, ainda, como alternativa de conquista financeira para auxiliar os familiares.

Resta-nos saber como e em quais circunstâncias as orientações para o Ensino Superior são dadas aos alunos surdos do Ensino Médio. Será que a escola não acredita no potencial desse aluno como estudante universitário? O Ensino Médio seria o limite para a educação dos surdos, já que as políticas do seu ingresso à universidade estão sendo postas recentemente, nesse contexto? Nessa via, é possível afirmar que existe um enorme abismo entre o que é proposto nas políticas afirmativas e o que se apresenta no contexto atual, sob a égide de uma universidade acessível e inclusiva. Embora haja uma demanda de legislação que apoie a eliminação das barreiras no acesso a essa etapa de ensino, inúmeros obstáculos impedem os surdos de se apropriarem dos conhecimentos valorizados pela universidade. Nesse caso específico, soma-se a ausência de práticas educacionais bilíngues para surdos, no país.

A temática é recente e, em face de tantas perguntas e poucas respostas, este estudo, como alguns outros (MANENTE; RODRIGUES; PALAMIN, 2007; CRUZ, 2007; BISOL et al., 2010; MOURA; HARRISON, 2010; DAROQUE; PADILHA, 2012; SILVA et al., 2012; ALBINO; SILVA, 2013; MARTINS; LACERDA, 2015), procura dar continuidade ao debate sobre essas questóes, evidenciando a necessidade do desenvolvimento de outros trabalhos a respeito, para firmar posicionamentos que favoreçam a maior presença desse público, no contexto universitário.

Entende-se como principais contribuições a visibilidade das questôes associadas à educação dos surdos, no que se refere ao prolongamento de sua trajetória enquanto estudantes e, sobretudo, fazer valer suas vozes para que ecoem e se projetem por espaços até então pouco percorridos. $\mathrm{O}$ caráter inovador do estudo aqui relatado se configurou na análise dos depoimentos de alunos surdos do Ensino Médio sobre sua própria trajetória educacional, colaborando para divulgar seus propósitos enquanto estudantes interessados em continuar sua formaçáo educacional.

Acredita-se, portanto, que os achados deste estudo possibilitarão novos caminhos, ou seja, subsídios para a ampliação das discussóes em relação à educação dos surdos e, sobretudo, às condiçóes de acesso e de permanência ofertadas pelas instituiçóes de Ensino Superior 
ao estudante surdo. Por fim, num futuro próximo, esperamos que, para o surdo, como para qualquer outro sujeito, a opção de querer ou não ingressar no Ensino Superior esteja baseada em sua vontade e não em condiçóes que o impeçam de exercer essa escolha.

\section{REFERÊNCIAS}

ALBINO, I.B.; SILVA, J.E.F. Estudantes com surdez/deficiência auditiva na Universidade Federal do Rio Grande do Norte - UFRN: vozes e desafios. In: SEMINÁRIO INTERNACIONAL INCLUSÃO EM EDUCAÇÃO: Universidade e Participação, 3., 2013, Rio de Janeiro. Anais... Rio de Janeiro: UFRJ, 2013. p.432-441.

BAKHTIN, M.; VOLOCHINOV, V.N. Marxismo e filosofia da Linguagem. 9.ed. São Paulo: HUCITEC, 1999.

BISOL, C.A. et al. Estudantes surdos no ensino superior: reflexôes sobre a inclusão. Cadernos de Pesquisa, Caxias do Sul, v.40, n.139, p.147-172, jan./abr. 2010.

BRASIL. Constituição da república federativa do brasil. Brasília, DF: Imprensa Oficial, 1988.

BRASIL. Ministério da Educação. Aviso Circular no 277, de 08 de maio de 1996. 1996a. Disponível em: <http://portal.mec.gov.br/arquivos/pdf/aviso_circular277.pdf>. Acesso em: 05 mar. 2015.

BRASIL. Ministério da Educação. Lei no 9.394, de 20 de dezembro de 1996. Lei de Diretrizes e Bases da Educação Nacional. Brasília, DF: Imprensa Oficial, 1996b.

BRASIL. Decreto no 3298, de 20 de dezembro de 1999. 1999a. Disponível em: http://www.planalto.gov. br/ccivil_03/decreto/d3298.htm. Acesso em: 06 jun. 2015.

BRASIL. Ministério da Educação e do Desporto. Parâmetros curriculares nacionais - adaptaçóes curriculares: estratégias para a educação de alunos com necessidades educacionais especiais. Brasília, DF: MEC/SEF/SEESP, 1999 b.

BRASIL. Lei no 10.098, de 19 de dezembro de 2000. Estabelece normas gerais e critérios básicos para a promoção da acessibilidade das pessoas portadoras de deficiência ou com mobilidade reduzida, e dá outras providências. Brasília, DF: Imprensa Oficial, 2000.

BRASIL. Senado Federal. Diretrizes nacionais para a educação especial na educação básica. Brasília, DF: MEC/SEESP, 2001.

BRASIL. Lei 10.436, de 24 de abril de 2002. Dispóe sobre a Língua Brasileira de Sinais - Libras e dá outras providências. Brasília, DF: Imprensa Oficial, 2002.

BRASIL. Ministério da Educação. Portaria n 3.284, de 7 de novembro de 2003. Brasília, DF: MEC/ SEESP, 2003.

BRASIL. Ministério da Educação. Decreto no 5.626, de 22 de dezembro de 2005. Brasília, DF: Imprensa Oficial, 2005.

BRASIL. Ministério da Educação. Secretaria de Educação Especial. Política nacional de educação especial na perspectiva da educação inclusiva. Brasília, DF: MEC/SEESP, 2008.

BRASIL. Instituto Nacional de Estudos e Pesquisas Educacionais Anísio Teixeira. Ministério da Educação. Sinopses estatísticas da educação superior - Graduação. Brasília, DF: INEP, 2014. Disponível em: <http://portal.inep.gov.br/superior-censosuperior-sinopse>. Acesso em: 21 set. 2015. 
BRASIL. Presidência da República. Lei 13.146. Institui a Lei Brasileira de Inclusão da Pessoa com Deficiência (Estatuto da Pessoa com Deficiência). Brasília, DF: Imprensa Oficial, 2015.

BRASIL. Instituto Nacional de Estudos e Pesquisas Educacionais Anísio Teixeira. Ministério da Educação. Sinopse estatística da educação superior 2015. Brasília, DF: INEP, 2016. Disponível em: http://portal.inep.gov.br/basica-censo-escolar-sinopse-sinopse. Acesso em: 15 mar. 2017.

CARVALHO, R.E. Educação inclusiva: como os pingos nos “is”. 9.ed. Porto Alegre: Mediação, 2013.

CRUZ, J.I.G. Consolidaçâo de uma trajetória escolar: o olhar do surdo universitário sobre o Ensino Superior. 2007. Dissertação (Mestrado em Educaçáo) - Centro Universitário Moura Lacerda, Ribeirão Preto, 2007.

DAROQUE, S.C.; PADILHA, A.M.L. Alunos surdos no Ensino Superior: uma discussão necessária. Comunicaçôes, Piracicaba, v.19, n.2, p.23-32, jul./dez. 2012.

GAVALDÃO, N. Estudantes surdos na educação superior: análise de professores sobre o contexto pedagógico. 2017. Dissertação (Mestrado em Educação) - Universidade Estadual Paulista, Faculdade de Filosofia e Ciências, Marília, 2017.

GÓES, M.C.R. Linguagem, surdez e educação. 4.ed. ver. Campinas: Autores Associados, 2012.

LACERDA, C.B.F. Intérprete de Libras: em atuação na educação infantil e no ensino fundamental. 6. ed. Porto Alegre: Mediação, 2014.

LACERDA, C.B.F.; BERNARDINO, B. M. O papel do intérprete de língua de sinais nas etapas iniciais de escolarização. In: LODI, A.C.B.; LACERDA, C.B.F. (Org.). Uma língua, duas escolas: letramento em língua portuguesa e língua de sinais nas etapas iniciais de escolarização. 4. ed. Porto Alegre: Mediação, 2014. p.65-80.

LEITE, L.P.; MARTINS, S.E.S. Fundamentos e estratégias pedagógicas inclusivas: respostas às diferenças na escola. São Paulo: Cultura Acadêmica; Marília: Oficina Universitária, 2012. Disponível em: https:// www.marilia.unesp.br/Home/Publicacoes/livro-fundamentos_leite_martins2012.pdf Acesso em: 11 set 2015 .

LODI, A.C.B. Educação bilíngue para surdos e inclusão segundo a Política Nacional de Educação Especial e o Decreto n. ${ }^{\circ}$ 5.626/05. Educação e Pesquisa, Sáo Paulo, v.39, n.1, p.49-63, jan./mar. 2013.

MANENTE, M.V.; RODRIGUES, O.M.P.R.; PALAMIN, M.E.G. Deficientes auditivos e escolaridade: fatores diferenciais que possibilitam o acesso ao Ensino Superior. Rev. Bras. Ed. Esp., Marília, v.13, n.1, p.27-42, 2007. Disponível em: http://www.scielo.br/pdf/rbee/v13n1/a03v13n1.pdf. Acesso em: 24 abr. 2014.

MARTINS, D.A.; LACERDA, C.B.F. Exame Nacional do Ensino Médio e acesso de estudantes surdos ao Ensino Superior Brasileiro. Pro-Posiçôes, Campinas, v.26, n.3. p.83-101, 2015. Disponível em: http:/www.scielo.br/scielo.php?script=sci_arttext\&pid=S0103-73072015000300083\&lng=en\&nrm=i so . Acesso em: 08 jan. 2016.

MARTINS, D.A.; LEITE, L.P.; LACERDA, C.B.F. Políticas públicas para acesso de pessoas com deficiência ao Ensino Superior brasileiro: uma análise de indicadores educacionais. Ensaio: aval. pol. públ. Educ., Rio de Janeiro. v.23, n.89, p.984-1014, 2015. Disponível em: http://www.scielo.br/ scielo.php?script=sci_arttext\&pid=S0104-40362015000400984\&lng=en\&nrm=iso . Acesso em 08 de janeiro de 2016.

MOURA, M.C.; HARRISON, K.M.P. A inclusão do surdo na universidade - mito ou realidade? Cadernos de Tradução, Florianópolis, v.2. n.26, p.333-358, 2010. 
OMOTE, S. Diversidade, educação e sociedade inclusiva. In: OLIVEIRA, A.A.S.; OMOTE, S.; GIROTO, C.R.M. (Org.). Inclusão escolar: as contribuiçôes da educação especial. São Paulo: Cultura Acadêmica; Marília: FUNDEPE, 2008. p.15-32.

PERLIN, G. T. Identidades surdas. In: SKLIAR, C. (Org.). A surdez: um olhar sobre as diferenças. 6.ed. Porto Alegre: Mediação, 2013. p.51-74.

QUADROS, R.M. Educação de surdos: a aquisição da linguagem. Porto Alegre: Artmed, 1997.

QUADROS, R.M.; KARNOPP, L.B. Lingua de sinais brasileira: estudos linguísticos. Porto Alegre: Artmed, 2004.

RODRIGUES, D. Dez ideias (mal)feitas sobre a educação inclusiva. In: . (Org.). Inclusão e educação: doze olhares sobre a educação inclusiva. Sáo Paulo: Summus, 2006. p.299-318.

SÁ, N.R.L. Cultura, poder e educação de surdos. 2.ed. São Paulo: Paulinas, 2010.

SÃO PAULO. (Estado). Secretaria da Educação do Estado de São Paulo. Resolução 38. Dispóe sobre a admissão de docentes com qualificação na Língua Brasileira de Sinais - Libras, nas escolas da rede estadual de ensino. São Paulo: Secretaria da Educação, 2009.

SÃO PAULO. (Estado). Secretaria da Educação do Estado de São Paulo. Resolução 61. Dispóe sobre a Educação Especial nas unidades escolares da rede estadual de ensino. São Paulo: Secretaria da Educação, 2014.

SILVA, H.M. et al. A inclusão de estudantes com deficiência no Ensino Superior: Revisão de literatura. Revista da Universidade Vale do Rio Verde, Três Coraçóes, v.10, n.2, p.332-342, ago./dez. 2012.

SILVA, R.C.D.; MARTINS, S.E.S.O. Acessibilidade no processo seletivo: primeiras providências para viabilizar a inclusão no ensino superior. In: CONGRESSO NACIONAL DE AVALIAÇÃO EM EDUCAÇĀO (CONAVE), 4., 2016, Bauru. Anais... Bauru: UNESP, 2016.

SKLIAR, C. Os estudos surdos em educação: problematizando a normalidade. In: (Org.). $A$ surdez: um olhar sobre as diferenças. 6. ed. Porto Alegre: Mediação, 2013. p.7-32.

VALENTINI, C.B.; BISOL, C.A. Inclusão no ensino superior: especificidades da prática docente com estudantes surdos. Caxias do Sul: EDUCS, 2012.

Recebido em: 28/10/2016

Reformulado em: 28/03/2017

Aprovado em: 19/04/2017 